\title{
Synthesis and characterization of hypoxia-mimicking bioactive glasses for skeletal regeneration
}

\author{
M. M. Azevedo ${ }^{a, b}$, G. Jell ${ }^{a, b}$, M. D. O'Donnell ${ }^{c}$, R. V. Law ${ }^{d}$, R. G. Hill ${ }^{e}$ and M. M. \\ Stevens ${ }^{\mathrm{a}, \mathrm{b}}$ \\ ${ }^{a}$ Department of Materials, Imperial College of London, South Kensington Campus, \\ London, SW7 2AZ, UK \\ ${ }^{\mathrm{b}}$ Institute for Biomedical Engineering, Imperial College of London, South Kensington \\ Campus, London, SW7 2AZ, UK \\ ${ }^{\mathrm{C}}$ RepRegen Ltd, Level 2, Bessemer Building, Imperial College London, SW7 2AZ, UK \\ d Department of Chemistry, Imperial College London, South Kensington Campus, \\ London, SW7 2AZ, UK \\ ${ }^{\mathrm{e}}$ Institute of Dentistry, School of Medicine and Dentistry, Barts and the London, Queen \\ Mary University, London, E1 2AT, UK
}

\begin{abstract}
The cellular response to hypoxia is vital for skeletal tissue development and regeneration. Numerous processes, including progenitor cell recruitment, proliferation and differentiation, are activated through the hypoxia pathway in a low oxygen pressure environment. Novel materials-based strategies designed to activate the hypoxia pathway are therefore of great interest for orthopaedic tissue engineering.

Here resorbable bioactive glasses (BG) were designed to activate the hypoxia pathway by substitution of $\mathrm{Co}^{2+}$ for $\mathrm{Ca}^{2+}$ in the $\mathrm{BG}$ and substitution of $\mathrm{Co}^{2+}$ and $\mathrm{Ca}^{2+} /+2 \mathrm{Na}^{+}$for $\mathrm{Si}^{4+}$. This allowed for the controlled release of cobalt, whilst controlling BG bioactivity (apatite-forming ability). Two series of soda-lime-phosphosilicate glasses were manufactured with increasing concentrations of cobalt. Compositions were calculated to maintain constant network connectivity $(2.13)$ by considering cobalt as an intermediate oxide in the first series, and as a network modifier in the second series. $\mathrm{Mg}^{2+}$ and $\mathrm{Zn}^{2+}$ were added to one of the $\mathrm{Co}^{2+}$-containing glasses to inhibit HCA formation since delay or inhibition of HCA formation is essential for the use of BG in soft tissues, as is the case of cartilage.
\end{abstract}

Cobalt was present in both the silicate and phosphate phases of the BG. In addition, evidence was found for it playing a dual role in the silicate phase, acting as both an intermediate oxide and taking part in the network as well as being a network modifying oxide. Consistent with an intermediate oxide role, the presence of cobalt in the BG was shown to decrease ion release. HCA formation was delayed with cobalt additions. $\mathrm{Mg}^{2+}$ and $\mathrm{Zn}^{2+}$ further delayed HCA formation.

Cobalt release was found to be proportional to cobalt content of the BGs enabling the controlled delivery of cobalt in therapeutic active doses.

\section{Introduction}

A major challenge in bone tissue engineering is the development of constructs that can both promote bone formation and stimulate the formation of new blood vessels (angiogenesis). In vivo, low oxygen pressure (hypoxia) plays a vital role in the development and regeneration of skeletal tissue. Hypoxia activates a series of cellular processes through the hypoxia pathway ${ }^{1}$, including stem cell recruitment ${ }^{2}$, angiogenesis ${ }^{3}$ and stem cell differentiation ${ }^{4-5}$. Under normoxic conditions, the hypoxia inducible factor $1 \alpha$ (HIF-1 $\alpha$, the transcription factor responsible for the activation of the hypoxia pathway) 
is constitutively synthesized in the cytoplasm but immediately degraded via proteosomes. However, under hypoxic conditions, HIF-1 $\alpha$ degradation is inhibited, and the stabilised transcription factor is translocated into the nucleus where it dimerizes with HIF-1 $\beta$. The newly formed HIF-1 dimer then binds to hypoxia responsive elements (HRE) present in target genes and recruits coactivator/inhibitor proteins, leading to their altered transcription ${ }^{1}$.

Activation of the hypoxic response can be essential for long bone formation ${ }^{6-9}$ and enhances fracture repair ${ }^{10}$. Under hypoxia osteoblasts increase expression of vascular endothelial growth factor (VEGF), an angiogenic growth factor central to the establishment and repair of blood vessel networks ${ }^{11}$. More recently, hypoxia has also been shown to stimulate the production of angiogenic factors by both mesenchymal stem cells $(\mathrm{MSC})^{2}$ - progenitor cells already used commercially in cartilage tissue engineering $^{12}$ - and by osteoblasts cultured in 3D constructs ${ }^{10}$. Currently one of the major problems in bone tissue engineering is the absence of a mature microvasculature ${ }^{5,}{ }^{13}$. Mimicking hypoxia by stabilizing HIF-1 $\alpha$ has therefore been suggested as an efficient way of regulating the expression of a large number of pro- and anti-angiogenic genes ${ }^{14}$. The HIF-1a pathway is also vital for cartilage development, homeostasis and regeneration. Oxygen and vascular gradients are of great importance during cartilage development ${ }^{15}$ and chondrocyte metabolism normally operates at low $\mathrm{O}_{2}$ tension due to the avascularity of cartilage $\mathrm{e}^{15-16}$. The hypoxia pathway is essential in enabling chondrocytes to adapt their metabolism to a low oxygen pressure environment ${ }^{15}$. Hypoxic conditions in vitro can help maintain cell phenotype in cultured primary chondrocytes, delaying the in vitro ageing (dedifferentiation) of these cells that occurs over time ${ }^{15}$. Materials capable of regulating the cellular hypoxia pathway therefore offer great potential in skeletal tissue regeneration.

Cobalt ions have been used extensively to mimic a hypoxic environment in vitro, due to a well-established stabilising effect on HIF-1 $\alpha^{11,17-19}$. However, exposure to high and/or prolonged concentrations of these ions has been shown to cause cell toxicity in vitro and pathologies in vivo, most likely via activation of redox pathways. A controlled ion release system is therefore vital for any tissue engineering (TE) strategy involving delivery of cobalt. One possible vehicle is that of cobalt-doped bioactive glasses ( $\mathrm{Co}^{2+} \mathrm{BG}$ ). The 45S5 Bioglass ${ }^{\circledR}$, a specific BG composition, is a soda-lime-phosphosilicate that does not become surrounded by fibrous tissue when implanted; instead it forms an intimate bond to bone ${ }^{20}$. Bioglass ${ }^{\circledR}$ has Federal Drug Administration (FDA) approval and is commercially available for several applications in hard tissue restoration, in products such as NovaBone ${ }^{\circledR}$, NovaMin ${ }^{\circledR}$, Perioglas ${ }^{\circledR}$ and Vitoss-BA ${ }^{\circledR} 21$. Several modified versions of 45S5 have been reported and different ions, such as strontium, magnesium or zinc, have been added to the initial composition with the aim of improving bone bonding and regeneration $22-24$.

In this study cobalt ions were incorporated into two series of bioactive glasses and the role of cobalt within the $B G$ network investigated. Due to cobalt's charge to size ratio, it can enter the silicate network, e.g. as $\left[\mathrm{CoO}_{4}\right]^{2-}$ species, but it can also act as a higher coordination-number network modifier ${ }^{25}$. According to the Zachariasen's rules ${ }^{26-27}$ and Dietzel's criterion ${ }^{28}$, cobalt may act as an intermediate oxide because of its relatively high charge to size ratio. If we consider $\mathrm{Co}$ (II), $\mathrm{CN}=4$ which is equivalent to $\mathrm{CoO}_{4}{ }^{2-}$ species, the cobalt charge to size ratio is 0.49 (value calculated based on data from ${ }^{29}$ ), very similar to magnesium $(0.45$ if $\mathrm{CN}=6$ and 0.52 if $\mathrm{CN}=4)$, that has been shown to play a dual role in the silicate network ${ }^{22}$. However, if we consider Co (II) but $\mathrm{CN}=8$, in which the cobalt could be considered isostructural to calcium, the cobalt charge to size ratio is 0.35 (value calculated based on data from $^{29}$ ), characteristic of a network modifier. Therefore, cobalt can also act as a network modifier, replacing bridging oxygens (BOs) for non-bridging oxygens (NBOs) in a similar fashion to calcium. The role of cobalt in the 
glass network will determine the network connectivity (NC) and the BG properties, such as ion release rates and hydroxycarbonated apatite (HCA) formation, will be affected.

Since one of the proposed applications for the hypoxia stimulating BG is in cartilage tissue engineering, zinc and magnesium ions were added to one of the BG compositions in order to decrease HCA formation ${ }^{30-32}$, which would be undesirable for soft tissue applications. These two ions have previously been used in TE for a number of different purposes, including as dopants in the production of hydroxycarbonated apatite ceramics $^{32}$, incorporation into polymeric microspheres ${ }^{33}$ and also doping in bioactive glasse $^{22,} \quad 24,{ }^{34-35}$. Magnesium can increase chondrocyte proliferation and redifferentiation $^{36-37}$ and zinc is involved in bone metabolism ${ }^{38}$. Moreover, both magnesium and zinc can improve osteoblast adhesion to scaffolds ${ }^{39-40}$ and promote osteogenic differentiation $^{35,38,41-42}$.

\section{Materials and methods:}

\section{Preparation of bioactive glasses}

Two series of cobalt BGs were prepared by the melt-quench route. The network connectivity was calculated at 2.13 assuming either an intermediate oxide or network modifier role for $\mathrm{Co}^{2+}$ (Table 1). The BG compositions were designed using the inorganic polymer model of soda-lime-phosphosilicate glasses with the general formula of $3 \mathrm{SiO}_{2} \cdot 0.07 \mathrm{P}_{2} \mathrm{O}_{5} \cdot(1.4-\mathrm{X}) \mathrm{CaO} .1 .6 \mathrm{Na}_{2} \mathrm{O} . \mathrm{XAO}(\mathrm{A}=\mathrm{Co}, \mathrm{Mg} \text { or } \mathrm{Zn})^{43}$. Cobalt oxide was added to the glass composition in different concentrations to produce two different glass series: a charge balanced series (CB) and a non-charge balanced series (NonCB), based on $\mathrm{Co}^{2+}$ acting as an intermediate oxide and network modifying oxide, respectively. For the $\mathrm{CB}$ series, the $\mathrm{BG}$ composition was designed in order to maintain a fixed network connectivity, assuming $\mathrm{Co}^{2+}$ substituted for $\mathrm{Si}^{4+}$ in the glass network (as a intermediate oxide). Thus, each mole of $\mathrm{SiO}_{2}$ content was replaced by one mole of $\mathrm{CoO}$ and one mole of $\mathrm{CaO}$. BGs with $\mathrm{Co}^{2+}$ contents of $0,1,2$, and 4 mole $\%$ were prepared. In the NonCB series $\mathrm{CoO}$ was substituted for $\mathrm{CaO}$, to give $\mathrm{Co}^{2+}$ contents of $0,0.5,1,2$, and 4 mole \%. All other BG components were kept constant. $\mathrm{MgO}$ and $\mathrm{ZnO}$ were added to a $2 \% \mathrm{Co}^{2+} \mathrm{BG}$ from the NonCB series to achieve 2 and 4 mole \%. Once the compositions were prepared they were transferred to a platinum-rhodium crucible and placed into the pre-heated furnace $\left(1400^{\circ} \mathrm{C}\right.$ for $\left.90 \mathrm{~min}\right)$ and the molten contents of the crucible were then quenched into deionised water. The granular glass frit was collected and dried in an oven at $100^{\circ} \mathrm{C}$. Finally, the glass frit was ground into a powder and sieved to obtain particles smaller than $38 \mu \mathrm{m}$. Glass powders were stored in a desiccator until used.

\section{Differential scanning calorimetry (DSC)}

Differential Scanning Calorimetry (DSC) was carried out on $50 \mathrm{mg}$ samples of $B G(<38$ $\mu \mathrm{m}$ particles) between 50 and $1050 \stackrel{\circ}{\circ} \mathrm{C}$ at a ramp rate of $10^{\circ} \mathrm{C} \mathrm{min}^{-1}$. A Polymer Laboratories Thermal Sciences was used and $\mathrm{Al}_{2} \mathrm{O}_{3}$ was used as the reference.

\section{Magic-angle-spinning nuclear magnetic resonance (MAS-NMR) spectroscopy}

${ }^{29} \mathrm{Si}$ and ${ }^{31} \mathrm{P}$ MAS-NMR were used to analyze the BG samples using a Bruker DSX-200 NMR spectrometer operating at Larmor frequencies of 39.77 and $81.9 \mathrm{MHz}$, respectively. Samples were packed into a $4 \mathrm{~mm}$ zirconia rotor and spun at the magic angle $\left(54.74^{\circ}\right)$ to remove anisotropy effects. The ${ }^{29} \mathrm{Si}$ and ${ }^{31} \mathrm{P}$ MAS-NMR spectra of the glasses were recorded at spinning frequencies from 3 to $12 \mathrm{kHz}$ using a Bloch decay pulse sequence for both silicon and phosphorus. The ${ }^{29} \mathrm{Si}$ and ${ }^{31} \mathrm{P}$ MAS-NMR samples 
were spun with a recycle delay time set to $2.0 \mathrm{~s}$ (although this was increased to $60.0 \mathrm{~s}$ if the glass species were not thought to be completely relaxed). All spectra were recorded at an ambient probe temperature with ${ }^{29} \mathrm{Si}$ referenced relative to polydimethylsilane (PDMS) and $85 \% \mathrm{H}_{3} \mathrm{PO}_{4}$ for ${ }^{31} \mathrm{P}$.

\section{Evaluation of ion release profiles from bioactive glasses}

The prepared BG samples were incubated in Tris buffer (45 mg of glass per $50 \mathrm{~cm}^{-3}$ Tris buffer or cell culture media) at $37 \stackrel{\circ}{\circ}$, in an orbital shaker at $120 \mathrm{rpm}$. At intervals, $5 \mathrm{~cm}^{-3}$ samples were collected, centrifuged and filtered. Inductively-coupled plasma optical emission spectrometry (ICP-OES) was performed on the resulting solutions and the concentrations of ions (silicon, calcium, sodium, phosphorus and cobalt) were calculated, based on standard solutions. ICP was performed using a Thermo Scientific iCAP 6000 Series ICP Spectrometer.

\section{Evaluation of hydroxycarbonated apatite (HCA) formation on bioactive glasses}

To assess HCA formation, $75 \mathrm{mg}$ of BG powder (particles $<38 \mu \mathrm{m}$ ) was added to $50 \mathrm{~cm}^{3}$ of simulated body fluid (SBF), prepared according to the method proposed by Kokubo ${ }^{44}$ in conical flasks. The samples were placed in an incubator at $37^{\circ} \mathrm{C}$ for $8 \mathrm{~h}, 16 \mathrm{~h}, 24 \mathrm{~h}, 7$ days, 14 days, 21 days and 28 days. At these time points, the powder was collected by filtering, sprayed with acetone and then air dried. The formation of apatite was characterized using a Genesis II Fourier transform infrared spectrometer, within a range of 600 to $1600 \mathrm{~cm}^{-1}$ and a resolution of $8 \mathrm{~cm}^{-1}$.

\section{Results and discussion:}

The hypoxia pathway activates cellular responses fundamental for normal tissue development and regeneration that might be vital for skeletal tissue engineering.

To develop a BG with the ability to activate the cellular hypoxia response in cells, cobalt oxide was added to the BG compositions in different mole \% (referred to as \% from now on) concentrations (Table 1). X-ray diffraction (XRD) analysis verified that the BGs were amorphous and not crystalline, as evidenced by a lack of sharp peaks in the traces (data not shown).

\section{Effect of $\mathrm{Co}^{2+}$ addition on the BG structure and dissolution properties}

Differential scanning calorimetry (DSC) was performed to determine the glass transition temperature $\left(T_{g}\right)$ of the BGs. This is the transition from a glass to a viscous liquid on heating and is seen in the DSC trace as a negative deviation from baseline. The effect of $\mathrm{Co}^{2+}$ addition on $\mathrm{T}_{\mathrm{g}}$ was compared for both the charge balanced $(\mathrm{CB})$ and non-charge balanced (NonCB) BG series (Fig. 1). In the CB series, $T_{g}$ remained constant until $2 \%$ $\mathrm{Co}^{2+}$ addition and then increased slightly. However, in the NonCB series, $\mathrm{T}_{\mathrm{g}}$ decreased with $\mathrm{Co}^{2+}$ addition in a concentration-dependent manner with $\leq 2 \% \mathrm{Co}^{2+}$, then increased with $4 \% \mathrm{Co}^{2+}$. In general, the lower the $\mathrm{T}_{\mathrm{g}}$ the weaker the bonds in the $\mathrm{BG}$ and the more easily degradable in a physiological environment. So, according to the data presented above, the addition of $\mathrm{Co}^{2+}$ has no significant effect on the $\mathrm{BG}$ structure of the $\mathrm{CB}$ series. The network connectivity of these BGs is constant (Table 1) as enough modifier $\left(\mathrm{Na}^{+}\right.$and $\left.\mathrm{Ca}^{2+}\right)$ was added to the $\mathrm{BG}$ to charge balance any $\left[\mathrm{CoO}_{4}\right]^{2-}$ species formed. The relaxation of the silicate part of the $B G$ network, which is of constant polymerisation across the CB series, will dominate the signal in the DSC trace, therefore it follows that $\mathrm{T}_{\mathrm{g}}$ does not change significantly. Alternatively two processes could be occurring resulting in no significant change in $T_{g}$, for example the creation of a weakly bonded 
cobalt complex species and also polymerisation of the silicate network. In contrast, as $\mathrm{Co}^{2+}$ is added to the NonCB series the BG structure initially becomes weaker and more easily disrupted. However at a $\mathrm{Co}^{2+}$ content of $4 \%$ the opposite seems to happen and $\mathrm{T}_{9}$ increases. Since in the NonCB series $T_{g}$ decreases abruptly with the incorporation of a small percentage of $\mathrm{Co}^{2+}$ in the $\mathrm{BG}$ composition and $\mathrm{Si}-\mathrm{O}$ bonds are expected to be stronger than the Co-O bonds, the DSC data suggests $\mathrm{Co}^{2+}$ is acting as an intermediate oxide, partially entering the silicate network. As $\mathrm{Co}^{2+}$ enters the network, $\mathrm{Co}-\mathrm{O}-\mathrm{Si}$ bonds replace the stronger Si-O-Si bonds and thus the BG structure becomes weaker and more easily disrupted. However, when more than $2 \% \mathrm{Co}^{2+}$ is added to the $\mathrm{BG}$ composition, the effect of replacing a network modifier $\left(\mathrm{Ca}^{2+}\right)$ with $\mathrm{Co}^{2+}$ seems to predominate. At higher concentrations, replacing $\mathrm{Ca}^{2+}$ with $\mathrm{Co}^{2+}$ increases the degree of polymerization of the silicate network again as more $\mathrm{Co}^{2+}$ acts as a modifier and less $\mathrm{Co}-\mathrm{O}-\mathrm{Si}$ bonds occur in the network and $\mathrm{T}_{\mathrm{g}}$ increases. The BG structure becomes stronger and less easily disrupted. In the CB series the data in Fig. 1 showed $T_{g}$ is constant until $2 \% \mathrm{Co}^{2+}$ is reached, whereupon it slightly increases. This suggests that $\mathrm{Co}^{2+}$ is acting partially as an intermediate oxide as the excess $\mathrm{Ca}^{2+}$ and $\mathrm{Na}^{+}$ions added to the $B G$ are charge balancing the cobalt complexes and not depolymerising the silicate network. The DSC data there indicates that possibly $\mathrm{Co}^{2+}$ is taking part in the silicate network and acting as modifying oxide in the BG structure. This behavior would parallel the behavior of other divalent cations with similar ionic sizes, such as $\mathrm{Mg}^{2+}$ and $\mathrm{Zn}^{2+}$, that have also been previously reported to act as both intermediate oxides and network and network modifiers in the BGs ${ }^{22,24}$.

If $\mathrm{Co}^{2+}$ is initially acting partially as an intermediate oxide and taking part in the silicate network, when replacing $\mathrm{Ca}^{2+}$ for $\mathrm{Co}^{2+}$ in the NonCB series, this should induce a change in the silicate $Q^{2}$ structure towards a $Q^{3}$ structure. On formation of the $\left[\mathrm{CoO}_{4}\right]^{2-}$ species additional network modifying cations are required to charge balance the 2- charge, hence the degree of polymerization of the silicate network will increase. This change in the network connectivity could influence the chemical shift in ${ }^{29} \mathrm{Si}$ MAS-NMR spectroscopy. In addition, it is also possible that $\mathrm{Co}^{2+}$ may charge balance the orthophosphate $\left(\mathrm{PO}_{4}\right)^{3-}$ units in the glass. ${ }^{31} \mathrm{P}$ MAS-NMR could also be influenced by the presence of $\mathrm{Co}^{2+}$ in the phosphate phase of the BG. Therefore, in order to further elucidate the role(s) of $\mathrm{Co}^{2+}$ in the glass structure, ${ }^{29} \mathrm{Si}$ and ${ }^{31} \mathrm{P}$ MAS-NMR were performed (Fig. 2 and Fig. 3, respectively).

The ${ }^{29}$ Si MAS-NMR spectra of the NonCB (Fig. 2a) and CB (Fig. 2b) series showed that the resonance was invarient ca. $-80 \mathrm{ppm}$ across the series and broadened out with the addition of $\mathrm{Co}^{2+}$. In both cases the linewidth increased with $\mathrm{Co}^{2+}$ addition (Fig. 2c) due to a paramagnetic effect of the unpaired electrons in the partially filled d-orbitals of the $\mathrm{Co}^{2+}$ ion. The $\mathrm{Q}^{3}$ shoulder characteristic of the silicate structure did not increase with addition of $\mathrm{Co}^{2+}$ to the BG. However, a correlation was found between the ${ }^{29} \mathrm{Si}$ MAS-NMR peak position (Fig. 2d) and the network connectivity, NC1 parameter (Table 1).

A shift downfield was observed in the $\mathrm{CB}$ series with the addition of $\mathrm{Co}^{2+}$. This may be due to either $\mathrm{Co}^{2+}$ entering the network as an intermediate oxide or $\mathrm{Co}^{2+}$ acting as a network modifier depolymerising the network. In the NonCB series, however, the position of the ${ }^{29} \mathrm{Si}$ MAS-NMR peak remains constant throughout the series. The same happens with the NC1 parameter, which was constant in the NonCB series and decrease in the $\mathrm{CB}$ BGs. As this correlation is usually used to determine the structural changes and $\mathrm{NC} 1$ was calculated assuming $\mathrm{Co}^{2+}$ is a network modifier, this data is consistent with a network modifier role for $\mathrm{Co}^{2+}$. The ${ }^{31} \mathrm{P}$ MAS-NMR spectra shows orthophosphate is present in the BG. The position of the ${ }^{31} \mathrm{P}$ peak does not significantly change with $\mathrm{Co}^{2+}$ addition; however, both ${ }^{29} \mathrm{Si}$ and ${ }^{31} \mathrm{P}$ MAS-NMR spectra (Fig. 2 and Fig. 3) broaden out with the addition of $\mathrm{Co}^{2+}$, which indicates that the $\mathrm{Co}^{2+}$ could be evenly distributed over the network units. The effect of paramagnetic cations is very difficult to analyse using the same approach as for alkali earth or alkali cations. The 
paramagnetic cations have many unpaired electrons that can interact with the nuclei and produce a number of different effects on the NMR spectrum ${ }^{45-46}$, including a reduction in spin-lattice relaxation, $T_{1}$, times and broadening of the resonance line. Whereas some reduction in spin-lattice relaxation, $T_{1}$, time is beneficial, for obtaining improved signalto-noise ratios, line broadening is detrimental, especially in MAS-NMR spectra of BGs where the peaks are already broad due to the variation in bond angles and distances in a disordered glass structure. In our ${ }^{29} \mathrm{Si}$ and ${ }^{31} \mathrm{P}$ MAS-NMR spectra both effects were observed (Fig. 2 and Fig. 3), but only for the CB series and not for the NonCB series. This difference, however, is associated with the compositional design rather than the role of the $\mathrm{Co}^{2+}$ cation. From the DSC, ${ }^{29} \mathrm{Si}$ and ${ }^{31} \mathrm{P}$ MAS-NMR data, $\mathrm{Co}^{2+}$ therefore appears to play a dual role in the silicate network depending on its concentration. This is also known to be the case for other divalent cations such as $\mathrm{Mg}^{2+}$ and $\mathrm{Zn}^{2+}{ }^{22,24}$ of similar ionic size.

Ion release profiles of the BGs in Tris buffer were analysed by ICP-OES (Fig. 4). The ion release profiles of the BGs from the NonCB series (Fig. 4 a-d) were more significantly affected by the addition of $\mathrm{Co}^{2+}$ than those of the CB series (Fig. 4 e-h). In the CB series the amount of $\mathrm{Si}^{4+}, \mathrm{Ca}^{2+}$ and $\mathrm{Na}^{+}$released were similar across all compositions. However, in the NonCB series the addition of $\mathrm{Co}^{2+}$ seemed to decrease the release rates of $\mathrm{Si}^{4+}, \mathrm{Ca}^{2+}$ and $\mathrm{Na}^{+}$ions. Initial $\mathrm{Si}^{4+}$ release is faster in those $\mathrm{BGs}$ with a low to zero $\mathrm{Co}^{2+}$ content (Fig. 4a), suggesting the intermediate oxide effect of $\mathrm{Co}^{2+}$ is predominant in this case. $\mathrm{Ca}^{2+}$ and $\mathrm{Na}^{+}$release significantly decreases with addition of $\mathrm{Co}^{2+}$ to the $\mathrm{BG}$ in a concentration-dependent manner (Fig. $4 \mathrm{~b}$ and $4 \mathrm{c}$ ). The decrease in $\mathrm{Ca}^{2+}$ release might be partly explained by the $<20 \%$ lower $\mathrm{Ca}^{2+}$ content of the $\mathrm{Co}^{2+} \mathrm{BGs}$. However, only $20 \%$ of the $\mathrm{Ca}^{2+}$ is replaced by $\mathrm{Co}^{2+}$ whereas the release of $\mathrm{Ca}^{2+}$ decrease by $50 \%$ in the NonCB4Co as compared to the 0Co. This alone cannot fully account for the difference. In the case of $\mathrm{Na}^{+}$, however, its lower release is only due to the effect of $\mathrm{Co}^{2+}$ in the $\mathrm{BG}$ network since its concentration is kept constant through out the NonCB series.

If $\mathrm{Co}^{2+}$ is acting as an intermediate oxide, the decrease of the ion release rates is easily explained. In the NonCB series the decreased ion release rates are due to the replacement of a network modifier $\left(\mathrm{Ca}^{2+}\right)$ by an intermediate oxide $\left(\mathrm{Co}^{2+}\right)$, which increases the degree of polymerization of the silicate network. In the CB series, a network former $\left(\mathrm{Si}^{4+}\right)$ is replaced by another ion with the same role $\left(\mathrm{Co}^{2+}\right)$, so there is no major effect on ion release rates. The ion release profiles are therefore in agreement with DSC data and suggest $\mathrm{Co}^{2+}$ acts partially as an intermediate oxide.

Ion release from BG was also followed over a four week time period (here only phosphate release is reported). Fig. 5 clearly shows that the phosphate concentrations in the buffer can be associated with the presence of $\mathrm{Co}^{2+}$ in the BG. In both the NonCB and the CB BG series (Fig. 5a and 5b, respectively), phosphate ions stay in solution for a longer time period with increasing concentrations of $\mathrm{Co}^{2+}$ in the $\mathrm{BG}$. For example, in the case of 0 Co $B G$ of the NonCB series, the phosphate concentration in the buffer fell to zero after $24 \mathrm{~h}$. However, with increasing concentrations of $\mathrm{Co}^{2+}$ in the BG, phosphate ions remained in solution for up to 15 days. This could be due to slower precipitation of the orthophosphate ions as HCA or amorphous calcium phosphates in the $\mathrm{Co}^{2+}$ containing BGs. $\mathrm{Si}^{4+}$ concentrations in solution are approximately constant over time and they are similar between the different BGs, which suggests the differences in phosphate concentration are not due to different release rates from the BG as degradability seemed to be similar in all BGs based on $\mathrm{Si}^{4+}$ release. The more persistent solubility of the phosphate ions (i.e. longer induction time for apatite formation) can then be explained by the formation of more stable complexes between $\mathrm{Co}^{2+}$ and phosphate than those formed between $\mathrm{Ca}^{2+}$ and phosphate. The fact that cobalt has more valence electrons and is more electronegative than calcium could explain the higher stability of the cobalt phosphate complexes. It is also possible that $\mathrm{Co}^{2+}$ affects the nucleation of 
HCA crystals as $\mathrm{Mg}^{2+}$ does, since these two ions have similar charge to size ratios. The decrease in nucleation rate would then explain the persistence of phosphate ions in solution with $\mathrm{Co}^{2+}$ addition to the BGs.

In both $\mathrm{BG}$ series controllable $\mathrm{Co}^{2+}$ release was achieved with the novel BGs through modification of the $\mathrm{Co}^{2+}$ content of the $\mathrm{BGs}$ (Fig. 6). Higher $\mathrm{Co}^{2+}$ release rates were expected in the $C B$ BG series regardless of $\mathrm{Co}^{2+}$ role in the $B G$ network. However, the data revealed the opposite, in agreement with the $T_{g}$ values, which also decrease more rapidly in the NonCB BG series. More importantly, $\mathrm{Co}^{2+}$ are released within a biologically active concentration range. In vitro ${ }^{47-48}$ and in $v^{2} \mathrm{O}^{49}$ studies indicate that the physiologically active concentration range is between 50-250 $\mu \mathrm{M}$ (3-15 ppm). Additionally, the $\mathrm{Co}^{2+}$-containing $\mathrm{BGs}$ were tested and shown to activate the hypoxia response in SaOs2 cells (G. Jell, M. M. Azevedo, A. Zapata, M. Woisetschlager, M. Stapountzi, R. Hill, M. M. Stevens, Hypoxia inducible factor (HIF) stabilizing bioactive glasses, manuscript under preparation).

\section{Effect of $\mathrm{Mg}^{2+}$ and $\mathrm{Zn}^{2+}$ addition on BG structure and dissolution properties}

Substitution of $\mathrm{Mg}^{2+}$ and $\mathrm{Zn}^{2+}$ for $\mathrm{Ca}^{2+}$ in the $\mathrm{Co}^{2+}$-containing $\mathrm{BG}$ resulted in a decrease in $\mathrm{T}_{\mathrm{g}}$ (Fig. 7). $\mathrm{Mg}^{2+}$ and $\mathrm{Zn}^{2+}$ can have a dual role in the BG network ${ }^{22,24}$, both acting as intermediate oxides. If they act like intermediate oxides, the presence of Si-O-M bonds ( $\mathrm{M}$ being $\mathrm{Mg}^{2+}$ or $\mathrm{Zn}^{2+}$ ) weakens the BG network because the newly created bonds are significantly weaker than $\mathrm{Si}-\mathrm{O}-\mathrm{Si}$ bonds. This explains the observed drop in $\mathrm{T}_{\mathrm{g}}$. However, if $\mathrm{Mg}^{2+}$ and $\mathrm{Zn}^{2+}$ act as network modifiers, we would expect $\mathrm{T}_{\mathrm{g}}$ to increase because their ionic radii are smaller than that of $\mathrm{Ca}^{2+}$. These results suggest that these two ions can enter the silicate network and act as intermediate oxides and are in agreement with data previously reported ${ }^{22,24}, 29,50-51$.

${ }^{29} \mathrm{Si}$ and ${ }^{31} \mathrm{P}$ MAS-NMR were performed on the $\mathrm{Mg}^{2+}$ - and $\mathrm{Zn}^{2+}$-containing BGs. A shift upfield of the silicon peak was observed with the addition of both $\mathrm{Mg}^{2+}$ and $\mathrm{Zn}^{2+}$ to the BG. However, the addition of each $\mathrm{Mg}^{2+}$ and $\mathrm{Zn}^{2+}$ separately did not result in any significant shift of the silicon peak (Fig. 8a). ${ }^{31} \mathrm{P}$ MAS-NMR spectra suggested that the phosphate phase of the BG was not affected by the addition of $\mathrm{Zn}^{2+}$. In contrast, the phosphate peak shifted to a more positive region of the spectra upon $\mathrm{Mg}^{2+}$ addition to the BG (Fig. 8b). This indicates that $\mathrm{Na}^{+}$increasingly associates with orthophosphate groups as $\mathrm{Ca}^{2+}$ is substituted for $\mathrm{Mg}^{2+}$, suggesting $\mathrm{Mg}^{2+}$ is entering the network as an intermediate oxide. The same effect has been previously reported to occur in a concentration dependent manner over a range of $\mathrm{Ca}^{2+}$ substitutions from $25-100 \%{ }^{22,51}$.

In agreement with published data, ${ }^{30,52-55}$ the dissolution study performed here demonstrated decreased $\mathrm{Si}^{4+}, \mathrm{Ca}^{2+}, \mathrm{Na}^{+}$and $\mathrm{Co}^{2+}$ release with the addition of both $\mathrm{Mg}^{2+}$ and $\mathrm{Zn}^{2+}$ to the BGs (Fig. 9). This was clearly seen for $\mathrm{Ca}^{2+}$ and $\mathrm{Na}^{+}$release (Fig. 9b and $9 \mathrm{c}$ ), and the effect was more pronounced with $\mathrm{Zn}^{2+}$ than with $\mathrm{Mg}^{2+}$ (Fig. 9a and 9d). These results can be explained by the possibility that these two metals may also act as network modifiers. Since both $\mathrm{Mg}^{2+}$ and $\mathrm{Zn}^{2+}$ have smaller ionic radii than $\mathrm{Ca}^{2+}$, replacing $\mathrm{Ca}^{2+}$ with either of these ions should result in a denser network, causing the $\mathrm{BGs}$ to be less reactive. Furthermore, $\mathrm{Mg}-\mathrm{O}$ and $\mathrm{Zn}-\mathrm{O}$ bonds are stronger than $\mathrm{Na}-\mathrm{O}$ and $\mathrm{Ca}-\mathrm{O}$ bonds. On the contrary, if $\mathrm{Mg}^{2+}$ and $\mathrm{Zn}^{2+}$ were to act as intermediate oxides and take part in the silicate network, the BG would become weaker due to the formation of $\mathrm{Si}-\mathrm{O}-\mathrm{M}$ and $\mathrm{M}-\mathrm{O}-\mathrm{M}$ bonds and this would increase ion release rates. However, in this instance, a further consideration is that in this scenario $\mathrm{Ca}^{2+}-$ a network modifier - is replaced by an intermediate oxide, which could decrease the BGs dissolution rates due to a greater degree of polymerization of their network. If $\mathrm{Mg}^{2+}$ and $\mathrm{Zn}^{2+}$ replace $\mathrm{Ca}^{2+}$ as network modifiers, the glass structure will also be strengthened since the ionic radii of 
$\mathrm{Mg}^{2+}$ and $\mathrm{Zn}^{2+}$ are smaller than that of $\mathrm{Ca}^{2+}$. In this case, the BG network will be tighter and ion release rates will decrease. These findings corroborate previous work ${ }^{22,}{ }^{24}$ and suggests these two ions can play a dual role acting to take part in the silicate network and acting to disrupt it.

\section{Bioactivity of and HCA formation on the bioactive glasses}

The ability of the BGs to form hydroxycarbonated apatite (HCA) according to the Kokubo protocol ${ }^{44}$ was studied. In this study the SBF test was used to assess the effect of $\mathrm{Co}^{2+}$, $\mathrm{Mg}^{2+}$ and $\mathrm{Zn}^{2+}$ addition to the glass on HCA formation, since HCA formation is undesirable if the $B G$ is to be used in soft tissue tissue engineering (eg. cartilage tissue engineering). This test has been previously used to assess BG bioactivity or bone binding ability in vitro. The limits of the SBF test in definitively predicting HCA formation and in vivo behaviour however should be considered ${ }^{56}$.

Fig. 10 shows the FTIR spectra of the different BGs from the NonCB series after incubation in SBF for 1, 2, 3 and 4 weeks. The peak at $570 \mathrm{~cm}^{-1}$ indicates the formation of an amorphous calcium phosphate layer. This peak splits into two peaks at $613 \mathrm{~cm}^{-1}$ and $574 \mathrm{~cm}^{-1}$, thus indicating formation of an apatite crystalline phase ${ }^{57-58}$. After 1 week in SBF only the OCo BG shows the presence of crystalline HCA (Fig. 10a). After 2 weeks (Fig. 10b), however, in the FTIR spectra of all $\mathrm{Co}^{2+}$-containing NonCB BGs peaks at $613 \mathrm{~cm}^{-1}$ and $574 \mathrm{~cm}^{-1}$ are observed, indicating the formation of the HCA crystalline layer on these BGs. The spectra of the $\mathrm{Mg}^{2+}$-containing BGs and the NonCB2Co4Zn BG only present the crystalline HCA peaks at $613 \mathrm{~cm}^{-1}$ and $574 \mathrm{~cm}^{-1}$ after 3 and 4 weeks incubation in SBF, respectively (Figs. $10 \mathrm{c}$ and $10 \mathrm{~d}$, respectively). Therefore, the presence of $\mathrm{Co}^{2+}, \mathrm{Mg}^{2+}$ and $\mathrm{Zn}^{2+}$ in the $\mathrm{BG}$ significantly delays the formation of a $\mathrm{HCA}$ layer and this delaying effect is strongest with $\mathrm{Mg}^{2+}$ and $\mathrm{Zn}^{2+}$. This result is in agreement with the dissolution data discussed above, since cobalt addition to the BGs was shown to decrease ion release, an essential step for HCA formation. The effect with $\mathrm{Mg}^{2+}$ and $\mathrm{Zn}^{2+}$ was already expected, as these two ions have been previously shown to delay HCA formation (S. Watts, R. V. Law, R. Hill, The influence of magnesium on the bioactivity of bioactive glasses, manuscript under preparation and ${ }^{24}$ ). Different mechanisms have been proposed to explain this effect. Some authors suggest $\mathrm{Zn}^{2+}$ can adopt a tetrahedral coordination and copolymerize with $\left[\mathrm{SiO}_{4}\right]$ tetrahedra, inducing complexation of the silicate network, which will decrease ion dissolution and delay HCA formation ${ }^{52,55}$. Other authors propose that the $\mathrm{Mg}^{2+}$ and $\mathrm{Zn}^{2+}$ ions can reduce the nucleation rate of apatite in solution and then bind to the surface of apatite crystals and delay the crystallization of amorphous apatite ${ }^{54,59-62}$. Since $\mathrm{Co}^{2+}$ has similar properties and seems to behave as $\mathrm{Mg}^{2+}$ and $\mathrm{Zn}^{2+}$ in the silicate network, it is possible that it has the same effect on HCA crystallization. The fact that $\mathrm{Zn}^{2+}$ has a stronger effect than $\mathrm{Mg}^{2+}$ has been previously reported by $\mathrm{Li}$ et al. and is in agreement with our data ${ }^{59}$.

\section{Conclusion}

Novel hypoxia-mimicking BGs were successfully developed introducing different amounts of $\mathrm{Co}^{2+}$ ions in the BG network. $\mathrm{Co}^{2+}$ was shown to be present in both silicate and phosphate phases of the synthesized BGs. In the orthophosphate phase of the $\mathrm{BGs}, \mathrm{Co}^{2+}$ seems to charge balance the orthophosphate groups. In the silicate phase of the BGs, however, $\mathrm{Co}^{2+}$ seems to play a dual role depending on the concentration at which $\mathrm{Co}^{2+}$ is present in the BG. As expected, addition of $\mathrm{Co}^{2+}$ to the $\mathrm{BG}$ was also shown to alter the BG properties. BG dissolution, ion release and HCA formation are delayed by inclusion of $\mathrm{Co}^{2+}$ in the $\mathrm{BG}$ in a concentration-dependent manner.

As previously reported, $\mathrm{Mg}^{2+}$ and $\mathrm{Zn}^{2+}$ also have a dual role in the silicate network as both network formers and network modifiers. A delay in HCA formation was achieved 
upon the addition of these two cations. The addition of either $\mathrm{Co}^{2+}, \mathrm{Mg}^{2+}, \mathrm{Zn}^{2+}$ or a combination of all three prevents HCA formation, which is essential and very promising for the use of these BGs in TE of soft tissues such as cartilage. More importantly, the BGs presented here allow a tailorable and controlled release of $\mathrm{Co}^{2+}$ ions within a biologically active concentration range indicating that the materials hold great promise as new hypoxia-mimicking materials for regenerative medicine.

\section{Acknowledgements}

This work was supported by EPSRC and Fundação para a Ciência e Tecnologia, Portugal (SFRH / BD / 36864 / 2007) for MMA. MMS thanks ERC Individual Investigator grant "Naturale".

\section{References}

1 G. L. Semenza, Science, 2007, 318, 62-64.

2 J. Malda, T. J. Klein and Z. Upton, Tissue Eng, 2007, 13, 2153-2162.

3 C. W. Pugh and P. J. Ratcliffe, Nat Med., 2003, 9, 677-684.

4 W. L. Grayson, F. Zhao, B. Bunnell and T. Ma, Biochem Biophys Res Commun., 2007, 358, 948-953.

5 L. G. Griffith and G. Naughton, Science, 2002, 295, 1009-1014.

6 D. Pfander, T. Kobayashi, M. C. Knight, E. Zelzer, D. A. Chan, B. R. Olsen, A. J. Giaccia, R. S. Johnson, V. H. Haase and E. Schipani, Development., 2004, 131, 2497-2508.

7 E. Zelzer, R. Mamluk, N. Ferrara, R. S. Johnson, E. Schipani and B. R. Olsen, Development, 2004, 131, 2161-2171.

8 E. Schipani, H. E. Ryan, S. Didrickson, T. Kobayashi, M. Knight and R. S. Johnson, Genes Dev., 2001, 15, 2865-2876.

9 P. J. Emans, F. Spaapen, D. A. M. Surtel, K. M. Reilly, A. Cremers, L. W. vanRhijn, S. K. Bulstra, J. W. Voncken and R. Kuijer, Bone., 2007, 40, 409-418.

10 C. Wan, S. R. Gilbert, Y. Wang, X. Cao, X. Shen, G. Ramaswamy, K. A. Jacobsen, Z. S. Alaql, A. W. Eberhardt, L. C. Gerstenfeld, T. A. Einhorn, L. Deng and T. L. Clemens, Proc Natl Acad Sci U S A, 2008, 105, 686-691.

11 H. H. Kim, S. E. Lee, W. J. Chung, Y. Choi, K. Kwack, S. W. Kim, M. S. Kim, H. Park and Z. H. Lee, Cytokine, 2002, 17, 14-27.

12 E. S. Place, N. D. Evans and M. M. Stevens, Nature Materials, 2009, 8, 457-470.

13 J. M. Kanczler and R. O. C. Oreffo, Eur Cell Mater., 2008, 15, 100-114.

14 R. K. Jain, P. Au, J. Tam, D. G. Duda and D. Fukumura, Nature Biotechnology, 23, 821-823.

15 J. Malda, D. E. Martens, J. Tramper, C. A. vanBlitterswijk and J. Riesle, Crit Rev Biotechnol., 2003, 23, 175-194.

16 M. B. Goldring, Best Pract Res Clin Rheumatol., 2006, 20, 1003-1025.

17 G. Chachami, G. Simos, A. Hatziefthimiou, S. Bonanou, P.-A. Molyvdas and E. Paraskeva, Am J Respir Cell Mol Biol., 2004, 31, 544-551. 
18 T. V. Lieshout, J. Stanisz, V. Espiritu, M. Richardson and G. Singh, Int J Oncol., 2003, 23, 745-750.

19 K. Peters, H. Schmidt, R. E. Unger, G. Kamp, F. Prols, B. J. Berger and C. J. Kirkpatrick, Mol Cell Biochem, 2005, 270, 157-166.

20 L. L. Hench, R. J. Splinter, W. C. Allen and T. K. Greenlee, J. Biomed. Mater. Res. 2, 1972, 5, 117 - 141.

21 L. Hench, J Mater Sci: Mater Med, 2006, 17, 967-978.

22 S. J. Watts, R. G. Hill, M. D. O'Donnell and R. V. Law, Journal of Non-Crystalline Solids, 2010, doi:10.1016/j.jnoncrysol.2009.04.074.

23 E. Gentleman, Y. C. Fredholm, G. Jell, N. Lotfibakhshaiesh, M. D. O'Donnell, R. G. Hill and M. M. Stevens, Biomaterials, 2010, doi:10.1016/j.biomaterials.2010.01.121.

24 M. Sengupta, in Department of Materials, Imperial College London, London, 2003.

25 W. A. Weyl, Coloured Glasses, SGT (Society of Glass Technology), 1954.

26 W. H. Zachariasen, J Am Chem Soc, 1932, 54.

27 B. E. Warren, J Am Cer Soc, 1938, 21.

28 A. Dietzel, Z. Electrochem, 1942, 48, 9.

29 W. Vogel, Glass chemistry, Springer-Verlag, Berlin, 1994.

30 R. L. Du and J. Chang, Biomed Mater Eng., 2006, 16, 229-236.

31 M. Kamitakahara, C. Ohtsuki, H. Inada, M. Tanihara and T. Miyazaki, Acta Biomaterialia, 2006, 2, 467-471.

32 S. J. Kalita and H. A. Bhatt, Materials science \& engineering. C, Biomimetic materials, sensors and systems, 2007, 27, 837-848.

33 N. R. Mercier, H. R. Costantino, M. A. Tracy and L. J. Bonassar, Biomaterials, 2005, 26, 1945-1952.

34 R. M. Day and A. R. Boccaccini, Journal of biomedical materials research. Part $A, 2005,73 \mathrm{~A}, 73-79$.

35 C. Vitale-Brovarone, E. Verné, L. Robiglio, P. Appendino, F. Bassi, G. Martinasso, G. Muzio and R. Canuto, Acta Biomaterialia, 2007, 3, 199-208.

36 F. Feyerabend, F. Witte, M. Kammal and R. Willumeit, Tissue Eng., 2006, 12, 3545-3556.

37 F. Feyerabend, Cytotherapy, 2006, 8, 60.

38 K. Ishikawa, Y. Miyamoto, T. Yuasa, A. Ito, M. Nagayama and K. Suzuki, Biomaterials, 2002, 23, 423-428.

39 H. Zreiqat, S. M. Valenzuela, B. B. Nissan, R. Roest, C. Knabe, R. J. Radlanski, H. Renz and P. J. Evans, Biomaterials, 2005, 26, 7579-7586.

40 W. Paul and C. P. Sharma, Journal of materials science, 2007, 18, 699-703.

41 H. Storriea and S. I. Stupp, Biomaterials, 2005, 26, 5492-5499.

42 M. Barron, Biomedical sciences instrumentation, 2007, 43, 248-253.

43 A. E. A. I. Elgayar, A.R. Boccaccini, R.G. Hill, Journal of Non-Crystalline Solids, 2005, 351, 173-183. 
H. T. T. Kokubo, Biomaterials, 2006, 27, 2907-2915.

G. Mali, A. Ristic and V. Kaucic, J. Phys. Chem. B, 2005, 109, 10711-10716.

K. J. D. MacKenzie and M. E. Smith, Multinuclear solid-state NMR of inorganic materials, 2002.

47 D. S. Steinbrech, B. J. Mehrara, P. B. Saadeh, J. A. Greenwald, J. A. Spector, G. K. Gittes and M. T. Longaker, Am J Physiol Cell Physiol., 2000, 278, C853-860.

48 A. Namiki, E. Brogi, M. Kearney, E. A. Kim, T. Wu, T. Couffinhal, L. Varticovski and J. M. Isner, J Biol Chem., 1995, 270, 31189-31195.

49 R. Buttyan, P. Chichester, B. Stisser, S. Matsumoto, M. Ghafar and R. Levin, J Urol., 2003, 169, 2402-2406.

50 E. Dowty, Phys Chem Minerals, 1987, 14, 122-138.

51 A. Pedone, G. Malavasi, C. Menziani, U. Segre and A. N. Cormack, J. Phys. Chem. C, 2008, 112, 11034-11041.

52 S. Haimi, G. Gorianc, L. Moimas, B. Lindroos, H. Huhtala, S. Räty, H. Kuokkanen, G. Sándor, C. Schmid and S. Miettinen, Acta Biomaterialia, 2009, 5, 3122-3131.

53 V. Aina, G. Malavasi, A. F. Pla and L. M. Morterra, Acta Biomaterialia, 2009, 5, 1211-1222.

54 E. Dietricha, H. Oudadesse, A. Lucas-Girot, Y. L. Gal, S. Jeanne and G. Cathelineau, Applied Surface Science, 2008, 255, 391-395.

55 L. Courthoux, J. Lao, J. M. Nedelec and E. Jallot, J. Phys. Chem. C, 2008, 112, 13663-13667.

56 L. J. Bohner M., Biomaterials, 2009, 30, 2175-2179.

57 G. Penel, G. Leroy, C. Rey, B. Sombret, J. P. Huvenne and E. Bres, Journal of Materials Science: Materials in Medicine, 1997, 8, 271-276.

58 O. P. Filho, G. P. LaTorre and L. L. Hench, Journal of Biomedical Materials Research, 1996, 30, 509-514.

59 X. Li, X. Wang, D. He and J. Shi, J. Mater. Chem., 2008, 18, 4103 - 4109.

60 D. B. Jaroch and D. C. Clupper, J Biomed Mater Res A., 2007, 82, 575-588.

61 R. Du, J. Chang, S. Ni, W. Zhai and J. Wang, J Biomater Appl., 2006, 20, 341360.

62 A. Saboori, M. Rabiee, F. Moztarzadeh, M. Sheikhi, M. Tahriria and M. Karimi, Materials Science and Engineering: C, 2009, 29, 335-340.

63 R. Hill, J Mat. Sci. Letts, 1996, 15, 1122-1125.

64 M. D. O'Donnell and R. G. Hill, Acta Biomaterialia, 2010, doi:10.1016/j.actbio.2010.01.006.

65 M. D. O'Donnell, S. J. Watts, R. V. Law and R. G. Hill, Journal of Non-Crystalline Solids, 2008, 354, 3554-3560.

66 M. D. O'Donnell, S. J. Watts, R. V. Law and R. G. Hill, Journal of Non-Crystalline Solids, 2008, 354, 3561-3566. 
Table 1 Designed compositions of the BG used in this study in mole percentages. The two columns on the right indicate the Network Connectivity (NC) of each glass calculated according to the method described by Hill ${ }^{63-66}$. Network connectivity 1 (NC1) was calculated assuming $\mathrm{Co}^{2+}$ to be a network modifier and network connectivity 2 (NC2) was calculated assuming $\mathrm{Co}^{2+}$ to be an intermediate oxide.

Fig. 1 Glass transition temperature $\left(T_{g}\right)$ as determined by DSC of NonCB and CB BG series as a function of mole percentage $(\mathrm{M} \%)$ of $\mathrm{Co}^{2+}$ ions in the $\mathrm{BG}$.

Fig. $2{ }^{29} \mathrm{Si} N M R$ spectra of the $\mathrm{Co}^{2+}$-containing BGs. (a) ${ }^{29} \mathrm{Si} \mathrm{NMR}$ spectra of the NonCB BG series. (b) ${ }^{29}$ Si NMR spectra of the CB BG series. Spectra for NonCB BG series: $(A)$ 0Co; (B) NonCB0.5Co; (C) NonCB1Co; (D) NonCB2Co; (E) NonCB4Co. Spectra for CB BG series: (F) OCo; (G) CB1Co; (H) CB2Co; (I) CB4Co). (c) Linewidth of the ${ }^{29}$ Si peaks as a function of $\mathrm{Co}^{2+}$ concentration in the BG for both NonCB and $C B$ BG series. (d) Position of the ${ }^{29} \mathrm{Si}$ peaks as a function of $\mathrm{Co}^{2+}$ concentration in the BG for both NonCB and $C B$ BG series.

Fig. $3{ }^{31} \mathrm{P}$ NMR spectra of the $\mathrm{Co}^{2+}$-containing BGs. (a) ${ }^{31} \mathrm{P}$ NMR spectra of the NonCB $B G$ series. (b) ${ }^{31} P$ NMR spectra of the $C B B G$ series. Spectra for NonCB BG series: $(A)$ 0Co; (B) NonCB0.5Co; (C) NonCB1Co; (D) NonCB2Co; (E) NonCB4Co. Spectra for CB BG series: (F) OCo; (G) CB1Co; (H) CB2Co; (I) CB4Co). (c) Linewidth of the ${ }^{31} \mathrm{P}$ peaks as a function of $\mathrm{Co}^{2+}$ concentration in the $B G$ for both NonCB and $C B$ BG series. (d) Position of the ${ }^{31} \mathrm{P}$ peaks as a function of $\mathrm{Co}^{2+}$ concentration in the $\mathrm{BG}$ for both NonCB and $C B$ BG series.

Fig. 4 Concentration of the different cations in Tris buffer as determined by ICP-OES as a function of time after incubation of BGs from both NonCB and CB BG series for up to 4h. (a-d) NonCB BG series; (e-h) CB BG series; (a and e) $\mathrm{Si}^{4+}$ concentration; (b and f) $\mathrm{Ca}^{2+}$ concentration; (c and g) $\mathrm{Na}^{+}$concentration; ( $d$ and h) $\mathrm{Co}^{2+}$ concentration.

Fig. 5 Phosphate concentration in Tris buffer as determined by ICP-OES as a function of time after incubation of BGs from both NonCB and CB BG series for up to 28 days. (a) NonCB BG series; (b) CB BG series; (c) $\mathrm{Mg}^{2+}$ - and $\mathrm{Zn}^{2+}$-containing $\mathrm{BG}$ s from the NonCB series.

Fig. 6 Cobalt concentration in Tris buffer as determined by ICP-OES as a function of mole percentage $(\mathrm{M} \%)$ of $\mathrm{Co}^{2+}$ after incubation of $\mathrm{BGs}$ from both NonCB and $\mathrm{CB} B \mathrm{BG}$ series for $4 \mathrm{~h}$.

Fig.7 Glass transition temperature $\left(\mathrm{T}_{\mathrm{g}}\right)$ as determined by DSC of $\mathrm{Mg}^{2+}$ - and $\mathrm{Zn}^{2+}$ containing BGs from the NonCB BG series as a function of the mole percentage (M\%) of both $\mathrm{Mg}^{2+}$ and $\mathrm{Zn}^{2+}$ ions in the BG.

Fig. $8{ }^{29} \mathrm{Si}$ and ${ }^{31} \mathrm{P}$ NMR spectra of the $\mathrm{Mg}^{2+}$ - and $\mathrm{Zn}^{2+}$-containing $\mathrm{BG}$ s from the NonCB BG series. (a) ${ }^{29} \mathrm{Si} N M R$ spectra, (b) ${ }^{31} \mathrm{P}$ NMR spectra. Spectra: (A) 0Co; (B) NonCB2Co; (C) NonCB2Co4Zn; (D) NonCB2CoMgZn; (E) NonCB2Co4Mg. 
Fig. 9 Concentration of the different cations in Tris buffer as determined by ICP-OES as a function of time after incubation of the $\mathrm{Mg}^{2+}$ - and $\mathrm{Zn}^{2+}$-containing BGs from NonCB BG series for up to $4 \mathrm{~h}$. (a) $\mathrm{Si}^{4+}$ concentration; (b) $\mathrm{Ca}^{2+}$ concentration; (c) $\mathrm{Na}^{+}$concentration; (d) $\mathrm{Co}^{2+}$ concentration.

Fig. 10 FTIR spectra of the BGs from the NonCB series after incubation in simulated body fluid (SBF) for up to 28 days. (a) FTIR spectra of the BGs after 7 days in SBF; (b) FTIR spectra of the BGs after 14 days in SBF; (c) FTIR spectra of the BGs after 21 days in SBF; (d) FTIR spectra of the BGs after 28 days in SBF. Spectra for NonCB BG series: (A) 0Co; (B) NonCB1Co; (C) NonCB2Co; (D) NonCB4Co; (E) NonCB2Co4Mg; (F) NonCB2CoMgZn; (G) NonCB2Co4Zn. 


\begin{tabular}{|c|c|c|c|c|c|c|c|c|c|c|}
\hline Series & BGs & $\mathrm{SiO}_{2}$ & $\mathrm{P}_{2} \mathrm{O}_{5}$ & $\mathrm{CaO}$ & $\mathrm{Na}_{2} \mathrm{O}$ & $\mathrm{CoO}$ & Zno & $\mathrm{MgO}$ & NC1 & NC2 \\
\hline & OCo & 49.46 & 1.07 & 23.08 & 26.38 & & & & 2.13 & 2.13 \\
\hline \multirow{7}{*}{$\begin{array}{l}\text { D } \\
0 \\
\text { Oे }\end{array}$} & NonCB0.5Co & 49.46 & 1.07 & 22.58 & 26.38 & 0.50 & & & 2.13 & 2.19 \\
\hline & NonCB1Co & 49.46 & 1.07 & 22.08 & 26.38 & 1.00 & & & 2.13 & 2.25 \\
\hline & NonCB2Co & 49.46 & 1.07 & 21.08 & 26.38 & 2.00 & & & 2.13 & 2.36 \\
\hline & NonCB4Co & 49.46 & 1.07 & 19.08 & 26.38 & 4.00 & & & 2.13 & 2.57 \\
\hline & NonCB2Co4Mg & 49.46 & 1.07 & 17.08 & 26.38 & 2.00 & & 4.00 & 1.97 & 2.62 \\
\hline & NonCB2CoMgZn & 49.46 & 1.07 & 17.08 & 26.38 & 2.00 & 2.00 & 2.00 & 1.97 & 2.62 \\
\hline & NonCB2Co4Zn & 49.46 & 1.07 & 17.08 & 26.38 & 2.00 & 4.00 & & 1.97 & 2.62 \\
\hline \multirow{3}{*}{ O } & CB1Co & 48.94 & 1.08 & 24.32 & 26.64 & 1.01 & & & 2.01 & 2.13 \\
\hline & CB2Co & 48.40 & 1.09 & 25.58 & 26.90 & 2.04 & & & 1.88 & 2.13 \\
\hline & CB4Co & 47.27 & 1.11 & 28.16 & 27.43 & 4.16 & & & 1.61 & 2.13 \\
\hline
\end{tabular}

Table 1. 


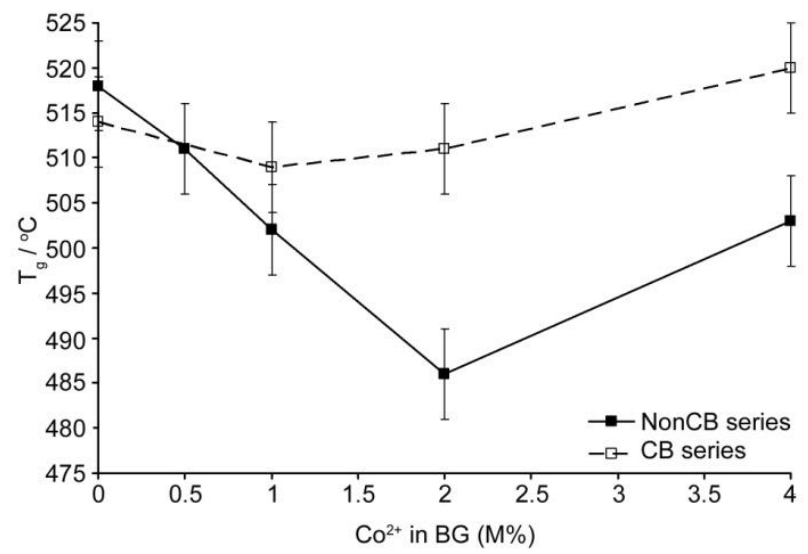

Fig. 1 

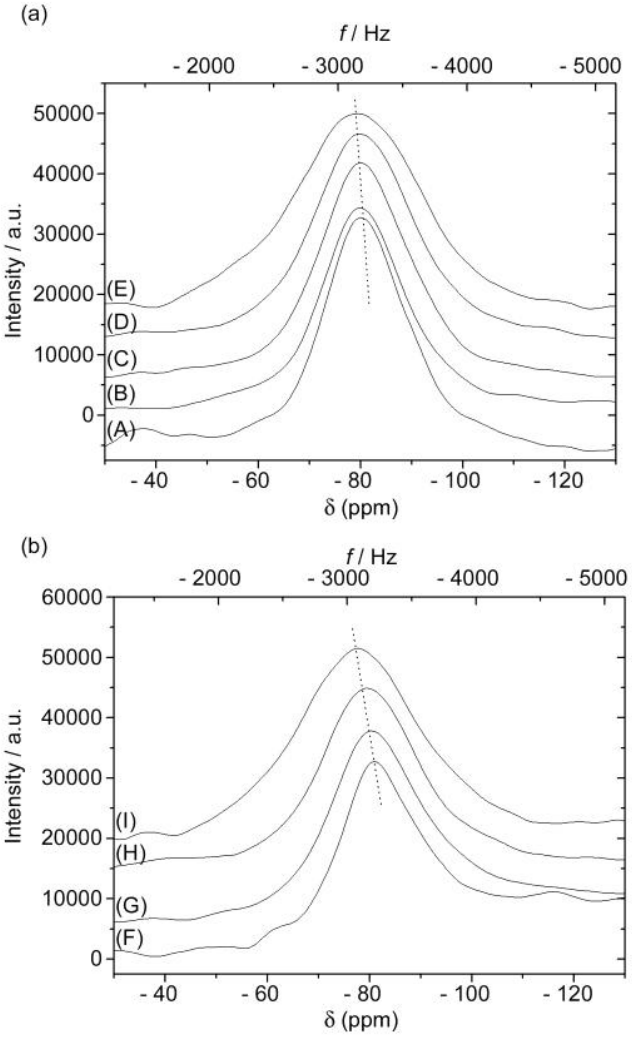

(c)

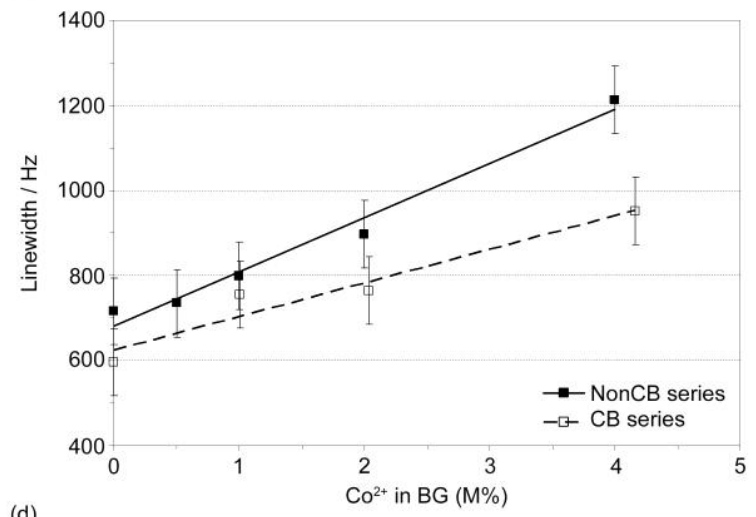

(d)

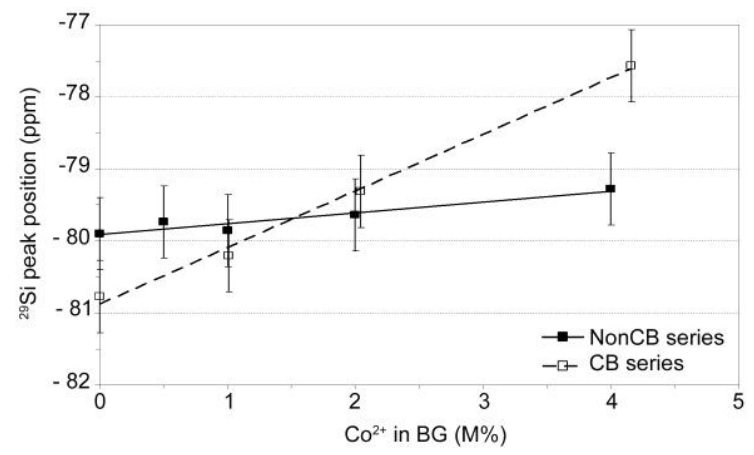

Fig. 2 
(a)

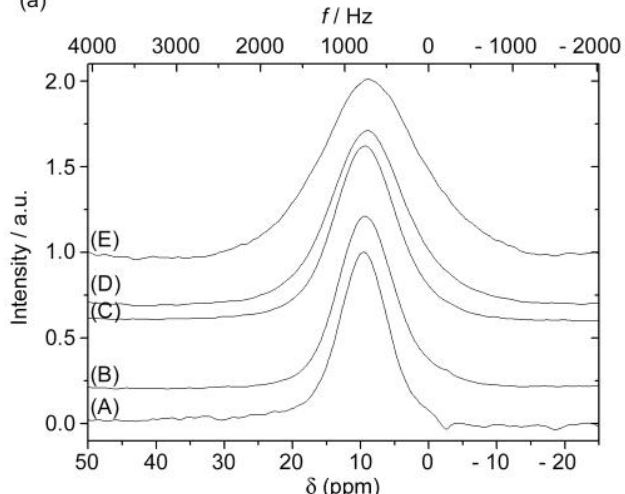

(b)

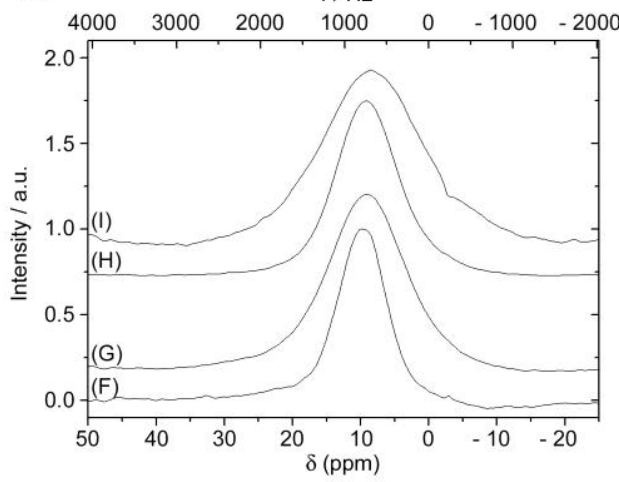

(c)

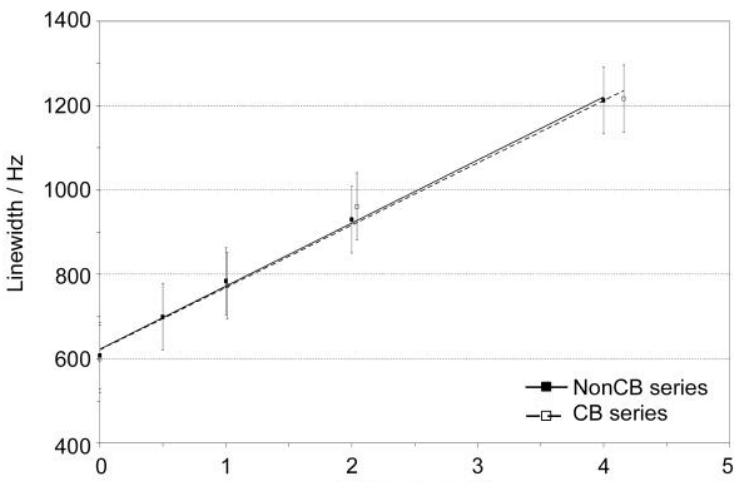

(d)

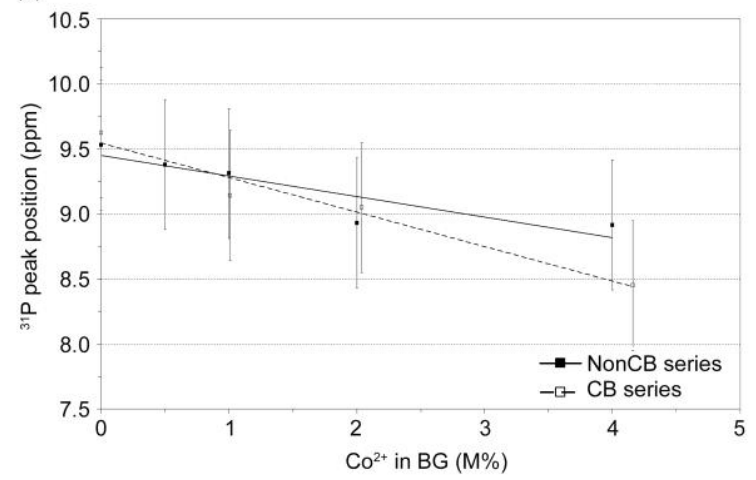

Fig. 3 
NonCB BG series
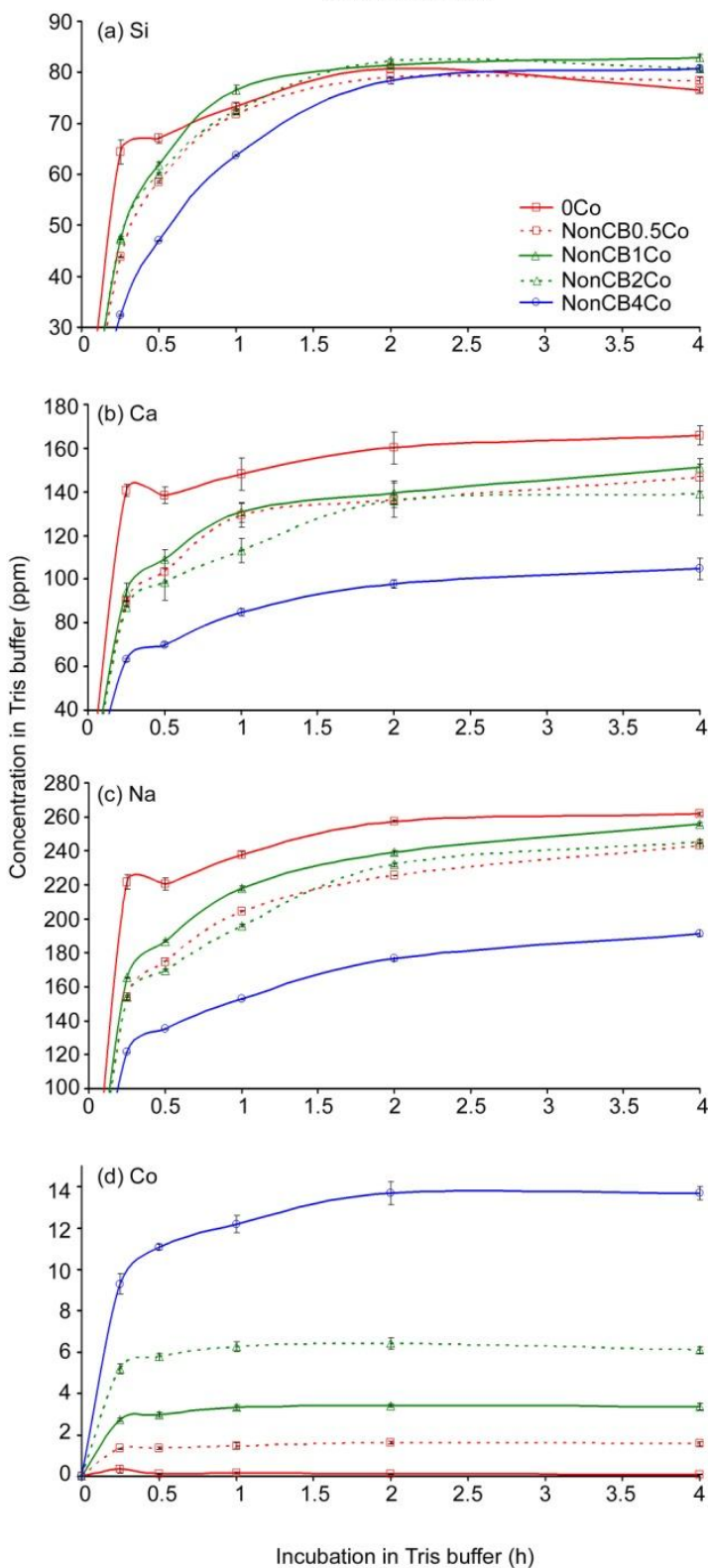

CB BG series
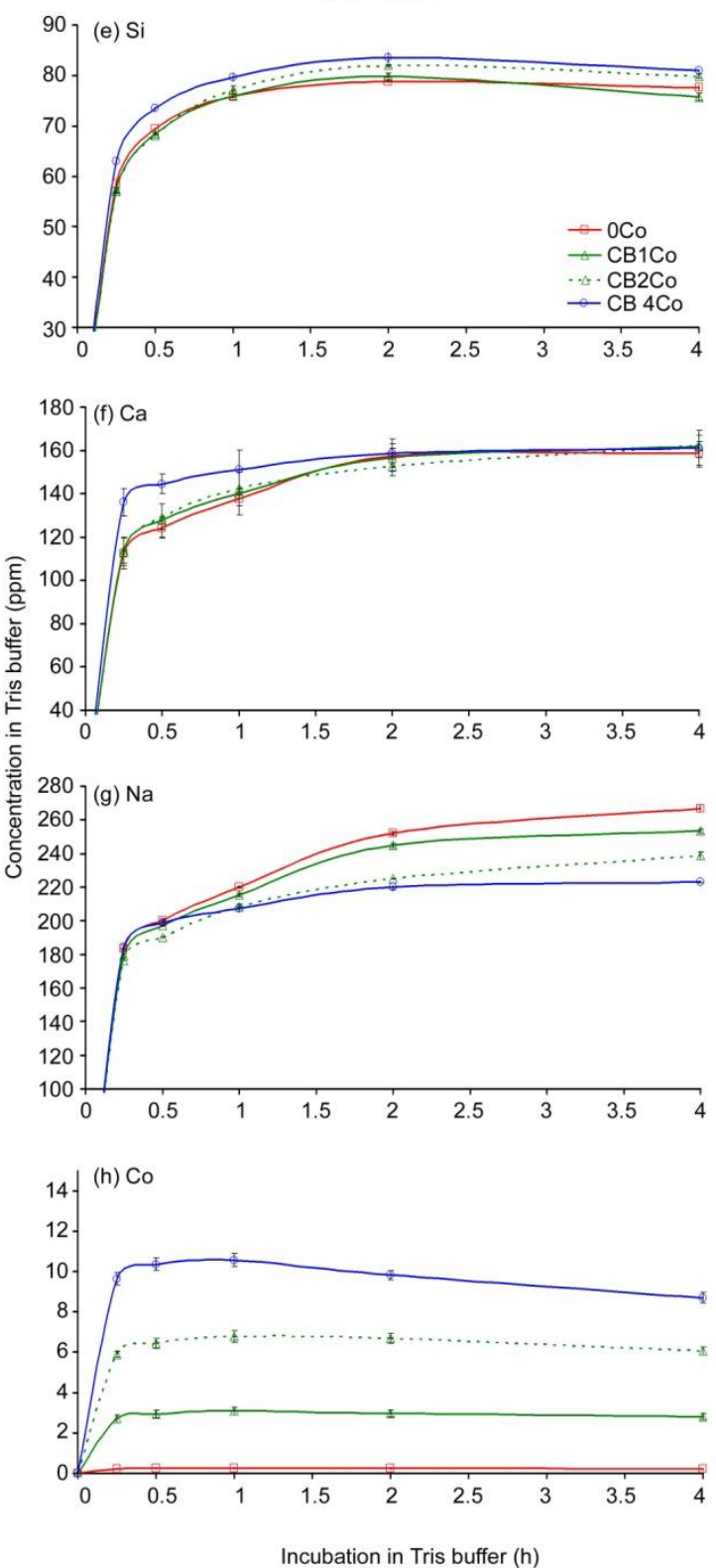

Fig. 4 


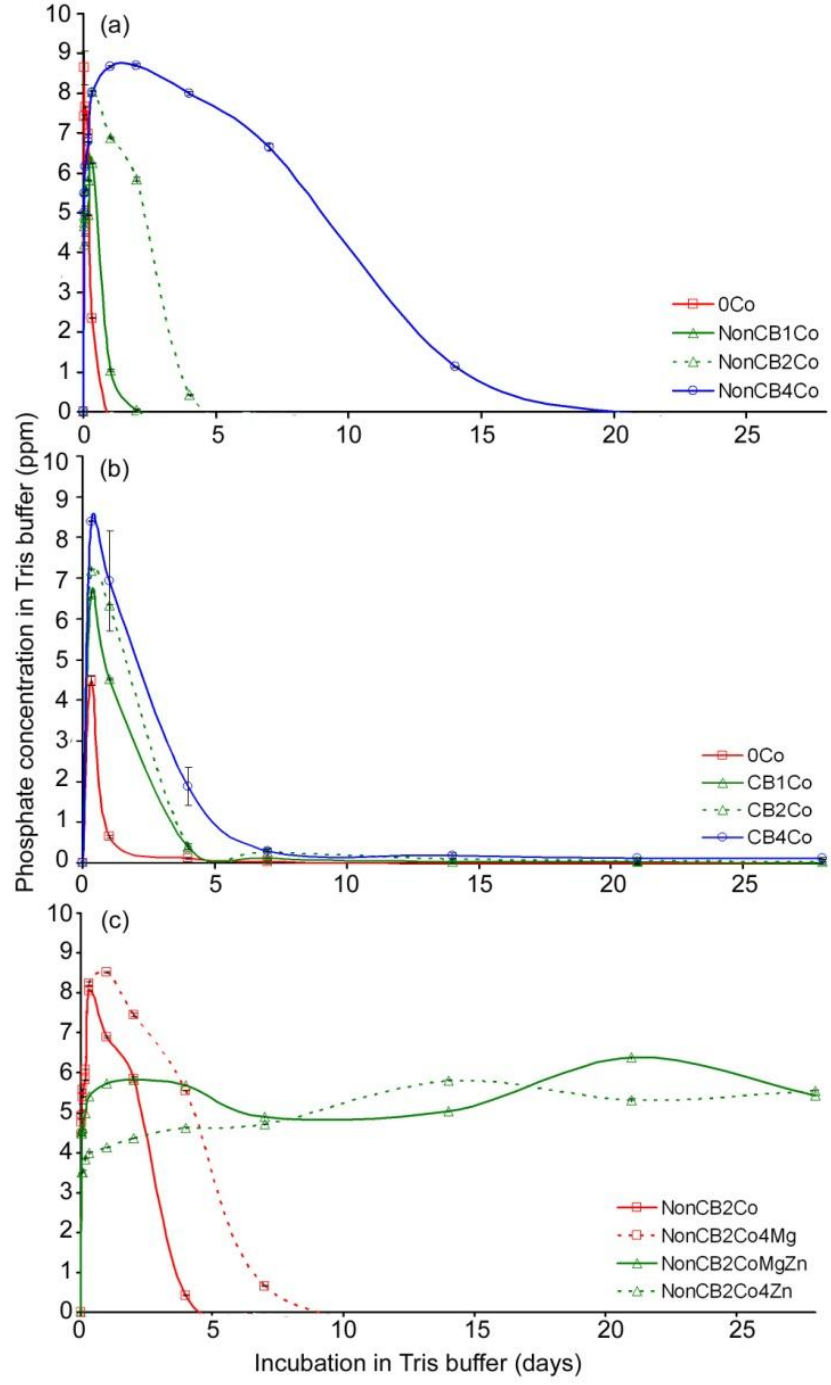

Fig. 5 


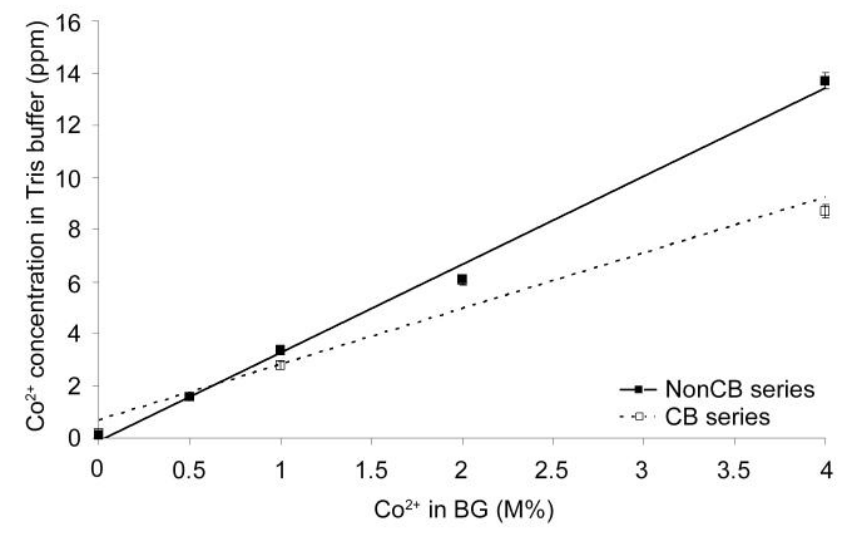

Fig. 6 


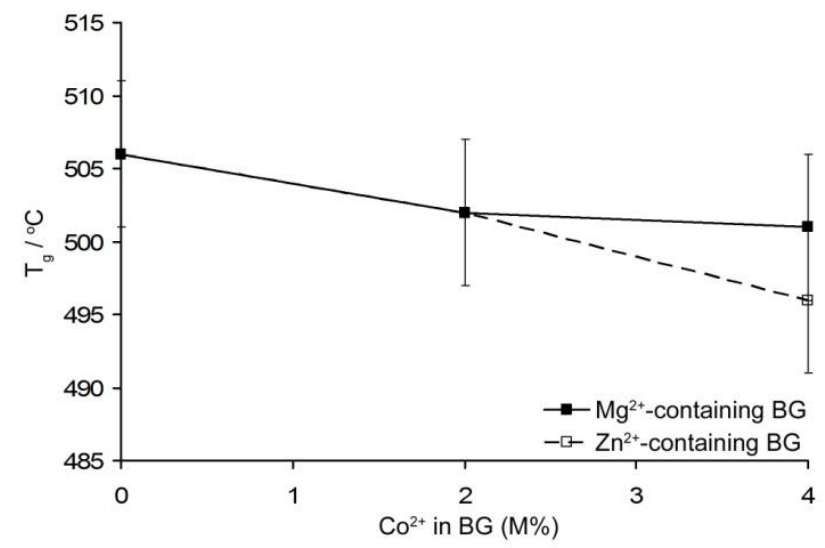

Fig. 7 


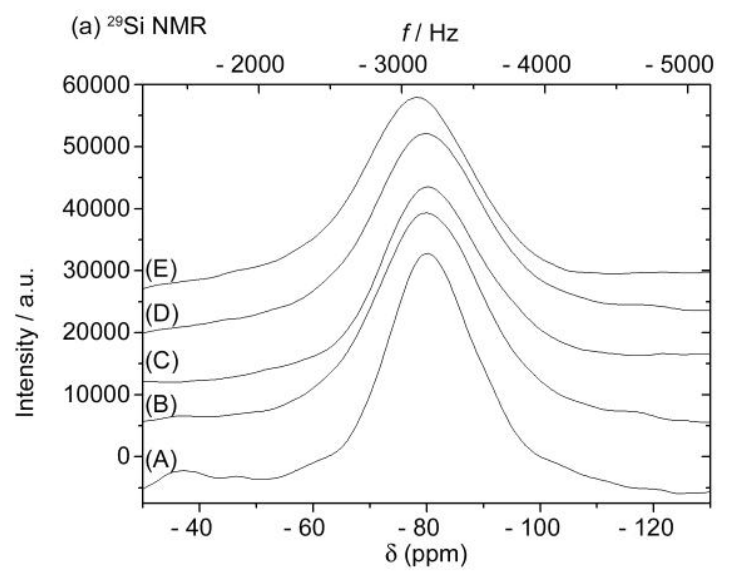

(b) ${ }^{31} \mathrm{P}$ NMR

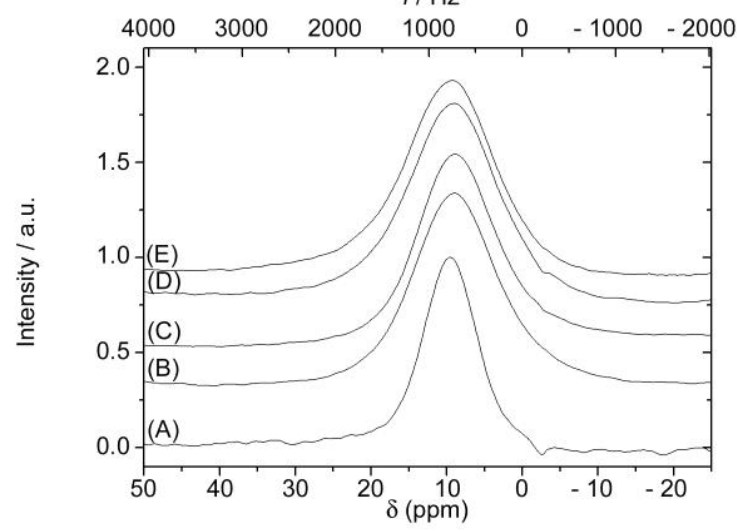

Fig. 8 

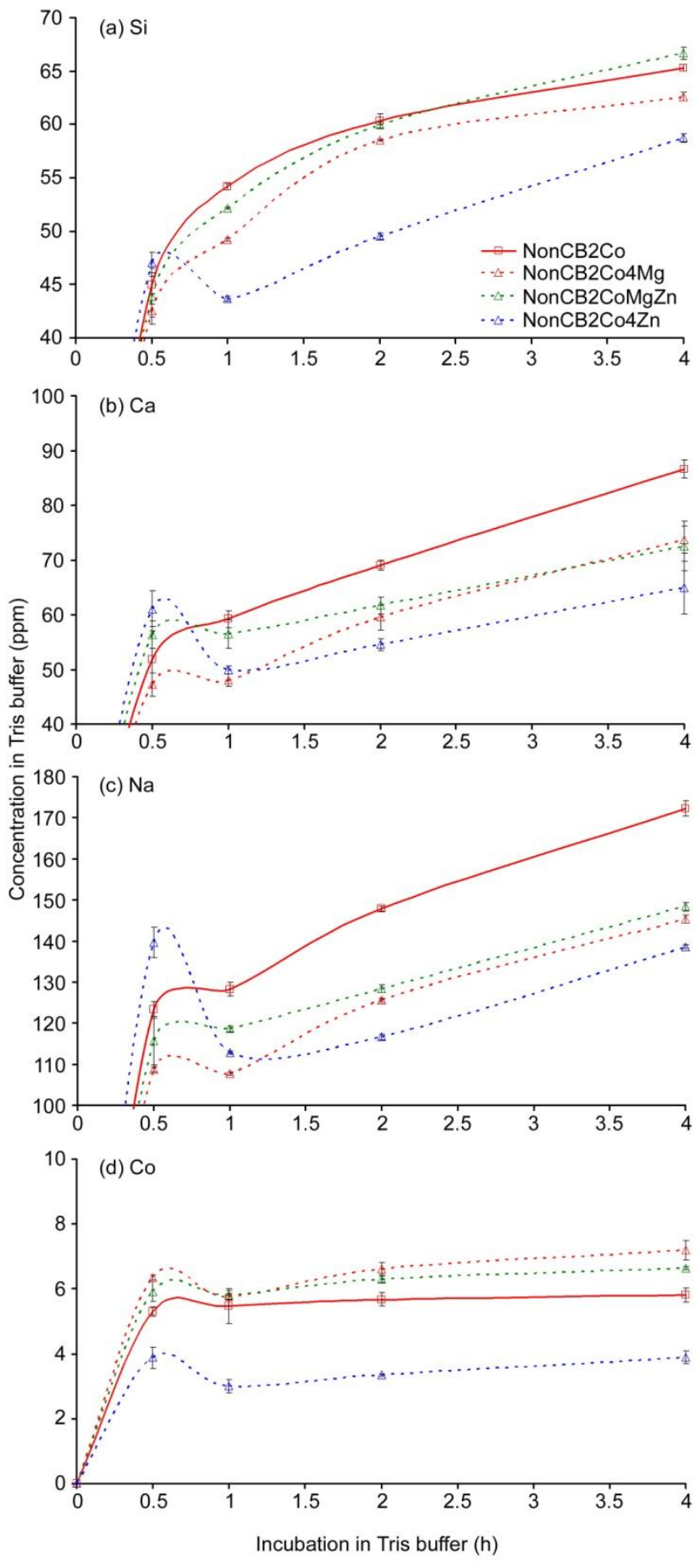

Fig. 9 
(a) 7 days

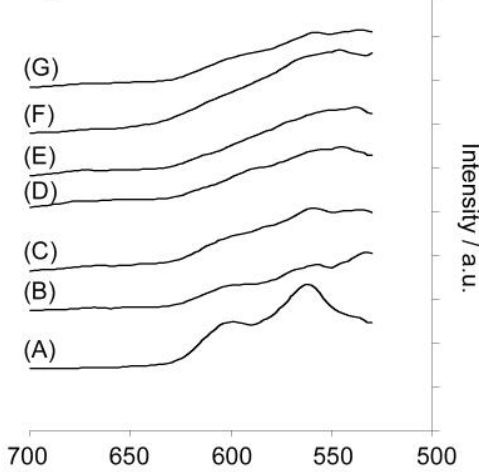

(b) 14 days

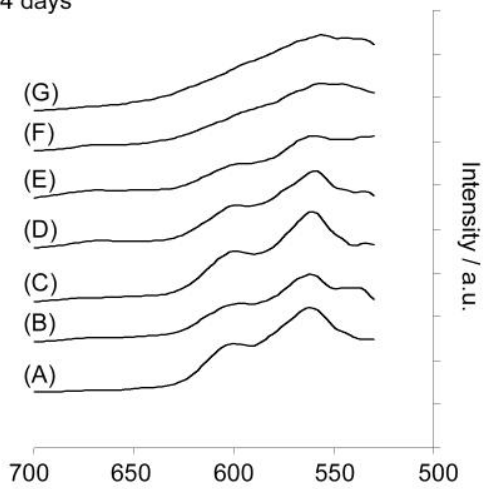

(c) 21 days

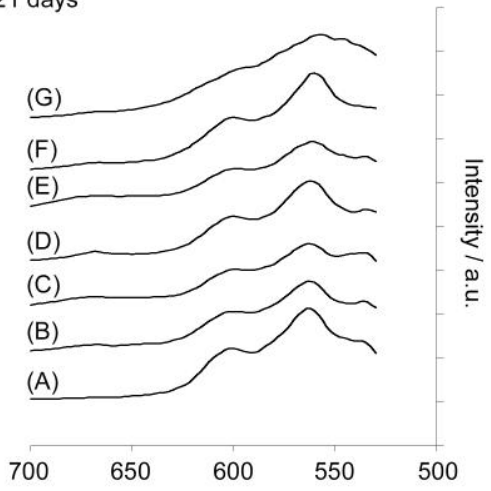

(d) 28 days

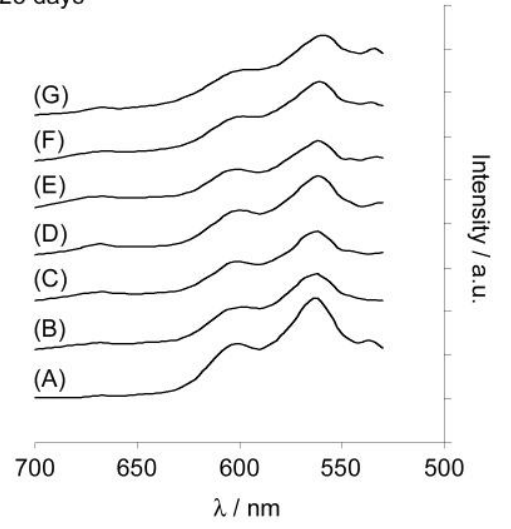

Fig. 10 